\title{
A STUDY TO COMPARE THE EFFECTIVENESS OF COMBINED OPEN AND CLOSED KINETIC CHAIN EXERCISES WITH MEDIAL PATELLAR TAPING IN PATIENTS WITH PATELLOFEMORAL PAIN SYNDROME
}

\author{
Eswar Reddy.K ${ }^{1}$, R. Kavya Priyanka ${ }^{1}$, B. Sandhya Rani ${ }^{2}$, K. Venugopal Reddy ${ }^{3}$, K. Sujitha \\ Chandrakala $^{1}$ \\ ${ }^{1}$ SIMS College of Physiotherapy, Mangaldas Nagar, Guntur, Andhra Pradesh,India. \\ ${ }^{2}$ N.G.Ranga Agricultural University,Bapatla,Guntur,Andhra Pradesh, India \\ ${ }^{3}$ Peoples Dental College, Madhya Pradesh,Bhopal, India \\ ${ }^{4}$ Peoples college,Madhya Pradesh,Bhopal, India
}

\section{ABSTRACT}

Background of the study: Patellofemoral pain syndrome(PFPS) is a syndrome characterized by knee pain ranging from severe to mild discomfort seemingly originating from the contact of the posterior surface of the patella (back of the kneecap) with the femur (thigh bone). Both open and closed kinetic chain exercises are effective in strengthening of the quadriceps muscle. It has been suggested that these exercises are used jointly in the management of PFPS, but no study to date has evaluated the effect of combined open and closed kinetic chain exercises on PFPS. Treatment of this condition is usually conservative, however the effectiveness of many treatments frequently used in clinical practice, including exercise and taping has not been established. Hence the purpose of this study is to compare the short term effects of combined open and closed kinetic chain exercises and medial patellar taping technique in patients with Patello Femoral Pain Syndrome

Methodology: 30 subjects with Patellofemoral Pain syndrome were selected for the study and randomized into two groups Group A and Group B.Group A received closed and open kinematic chain excercises for 30 minutes 5 days a week for 6 weeks and Group B were treated with patellar taping for a period of 6wks.

Outcome Measures: Pre and Post test values of all the subjects were evaluated using Visual Analog Scale(VAS) and kujala functional knee score.

Result: The results has revealed that there is significance noted in Group A $(p<0.0001)$ when compared to group B .Significant difference was also noted in both outcome scales vas and kujala functional score.

Conclusion: The results of this study have shown significant reduction of pain and improvement in functional ability of patients with patellofemoral pain sydrome with combined open and closed kinetic chain exercises(Group A) when compared to (Group B) that is medial patellar taping.

Key words: Patellofemoral Pain Syndrome, combined open and closed kinetic chain exercises, medial patellar taping.

\section{INTRODUCTION}

Patellofemoral pain syndrome which is also known as anterior knee pain in the literature is the most common aliment of knee in athelete and nonathelete adult youth. ${ }^{1}$ Incidence of this problem was reported to be $7 \%$ to $15 \%$ most often involving the women and youth ${ }^{2}$. Main symptom of this condition is diffuse retro patellar and peri patellar pain with no specific pathology which exacerbated while activities

*Corresponding author:

Email: thisiseshwarphysio@gmail.com

http://dx.doi.org/10.20530/IJTA $33 \quad 13-19$

ISSN 2320-138X @ 2016 such as stair ascent and descent, prolonged sitting, squatting, kneeling, running and jumping ${ }^{3}$. In these patients with this syndrome muscular function decreases ${ }^{4}$ Generally the patient may experience some degree of functional disability as a result of pain and decreases functions of knee ${ }^{5}$

There are a lot of theories regarding pathogenesis of patellofemoral pain syndrome, including muscle imbalance among the quadriceps and hamstring's, tensor fascia lata, gluteus medius, vastus medialis and vastus lateralis, ${ }^{6}$ mal-alignment of lower extremities, ${ }^{7}$ over use injuries, ${ }^{8}$ ligament and cartilage injuries of the knee, ${ }^{9}$ muscle imbalance between vastus medialis and vastus lateralis and patella maltracking in trochlea groove 
of femur and patellar motions is the theory mostly accepted by the author's ${ }^{10}$. Lateral patellar motion results in change in pressure distribution on the articular surfaces and also concentration and increased stress on lateral facet of patella, which in turn leads to patellar pain and patellofemoral pain syndrome ${ }^{11}$.

The author's suggested various conservative treatments to manage Patellofemoral Pain Syndrome. Strengthening of quadriceps by focusing on retraining of the vastus medialis oblique which stabilizes the patella in trochlea groove is the most commonly used and highly accepted procedure in management of patellofemoral pain syndrome known as "Golden standard"12 evidence supports exercise therapy in management ${ }^{13}$.

Open kinetic chain exercises are the traditional method of strengthening the quadriceps muscle, which have been used since past years but closed kinetic exercises are remarkably used during recent years $^{14}$. One of the reason to use closed kinetic chain exercises is that they are similar to activities of daily living i.e they are functional ${ }^{15}$ on the other hand low stress is composed on patellofemoral joint in closed as compared to open kinetic chain exercises ${ }^{16}$. The studies comparing the effect of open and closed kinetic chain exercises on patellofemoral pain syndrome found no remarkable difference between them. Hence combined open and closed kinetic chain exercises in management of patellofemoral pain syndrome were suggested ${ }^{17}$. However, in review of literature there was no study that evaluated the effect of combined open and closed kinetic chain exercises on patellofemoral pain syndrome.

The technique of patellar taping can be used in an attempt to not only unload the soft tissues but also maintain a sustained low load that can stretch the adaptively shortened retinacular tissue. There is some debate in the literature about the effect of tape on the patellofemoral joint. What is clear is that tape relieves symptoms.Is Patellar Taping Effective? It has been fairly well established that taping the patella relieves pain, although the mechanism of the effect is still being debated in the literature. It has been found that taping the patella of a symptomatic individual, such that the pain is decreased by $50 \%$, results in an earlier activation of the VMO relative to the vastus lateralis (VL) on both step-up and stepdown.
Medial patellar taping was significantly better than lateral or neutral tape for pain scores, symptom change, and patient preference. In this elderly osteoarthritic group, medial patellar taping resulted in a $25 \%$ reduction in knee pain.Some investigators have found that tape changes patellofemoral angle and lateral patellar displacement, but congruence angle is not changed.No studies have compared open and closed kinetic exercises with taping. Hence this study aims to compare both

\section{METHODOLOGY}

All subjects diagnosed with patellofemoral pain syndrome were screened for inclusion and exclusion criteria. The subjects with the age group of 30-50 years were included in the study.Both males and females were included.Patients with symptoms of patellofemoral pain syndrome for least 6 months dignosed by an orthopaedician and referred to physiotherapy department were included.Subjects with history of truma to the patella or knee following fracture,subluxation dislocation,ligament injuries,skin allergy to taping, sensory or circulatory problems were excluded from the study.Also,subjects with referred pain from the spine,or other body parts to the knee and patella were excluded from the study. The nature and purpose of study was explained to subjectsbefore recruiting them in the study. Informed consent form was taken from every subject.

\section{PROCEDURE}

30 subjects were selected for study and were randomized into two groups Group A and Group B. Group A subjects received combined open and closed chain kinetic chain excercises, whereas Group $B$ subjects received medial patellar taping.Group A received the following open and closed kinetic chain excercises 4 times a week for 6 weeks. They are:

\section{Open Kinetic Chain Exercises:}

These exercises are as follows:

1) Quadriceps isometrics in supine position (Figure 1)

2) Terminal knee extension in supine position

3) Hip adduction in lateral decubitus position

\section{Closed Kinetic Chain Exercises:}

In this subjects perform :

1) Semi squat with hip adduction and internal rotation 
(a)

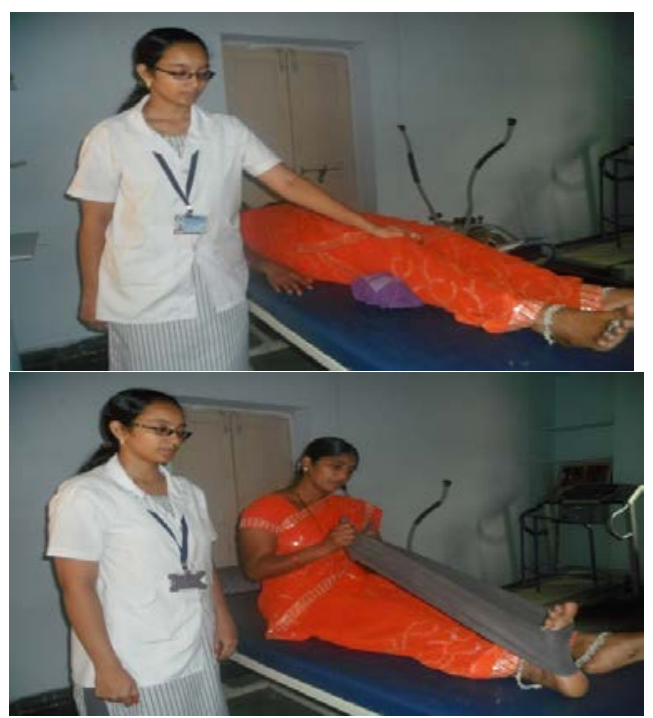

Fig. 1. Showing (a) Quadriceps isometric exercise (closed kinetic chain exercise) and (b)Terminal knee extension exercise with elastic band (open kinetic chain exercise)

2) Terminal knee extension with elastic band (Figure 2)

3) Adductor squeeze in crook lying position.

Both Group A and Group B subjects were assessed for pain using VAS and function using KUJALA scale prior to study after obtaining informed consent.

Group B subjects were treated with medial patellar taping.The knee is shaved $12 \mathrm{hrs}$ prior to taping to remove hair. The patient is made to lie supine.The skin is cleaned and dried removing any grease or sweat.Low irritant Fixomull tape is applied as an under-wrap to reduce the likelihood of skin (a)

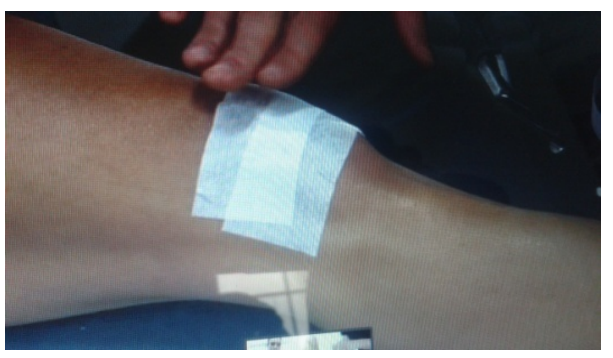

(b)

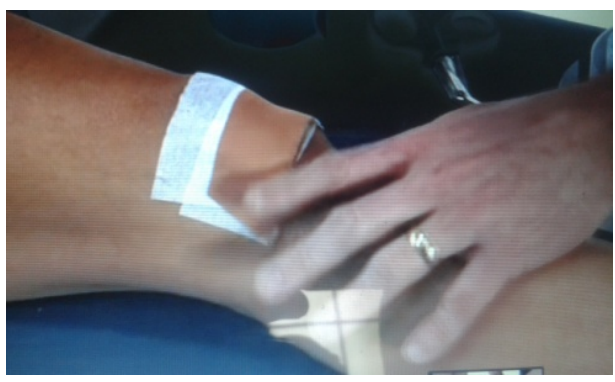

(c)

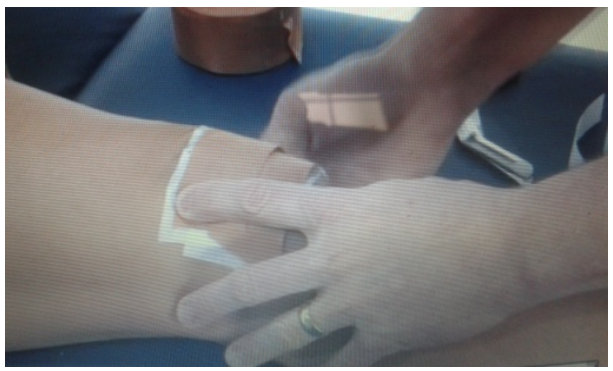

Fig. 2. Showing (a) Application of low irritant fixomull tape,(b) application of medial tape, (c) completed medial patellar taping

outcome is assessed using VAS and KUJALA knee functional scale.

Data Presentation And Statistical Analysis

Table 1: Comparison between pre and post values for vas in group A

\begin{tabular}{lcccc}
\hline & Mean value & Standard deviation & t-value & p-value \\
\hline PRE & 7.6 & 0.9856 & 8.360 & $<0.001$ \\
POST & 3.466 & 1.642 & & \\
\hline
\end{tabular}

irritation with rigid sports tape over the top of this(Figure 2 a).Tape is applied to the lateral aspect of the patella(Figure $\mathbf{2}$ b).The patella is glided medially and the tape anchored to the skin over the medial aspect of the knee(Figure $\mathbf{2} \mathbf{c}$ ). The subject is asked not to wet the tape.The patellar tape is removed every 3 days and new tape is applied upto 6 weeks.At the end of 6 weeks,pain and functional

\section{RESULTS}

Comparision between pre and post test values of Group A(open combined with closed kinetic chain exercise)considered extremely significant with $p$ value $<0.0001$.Comparision of pre and post test values of Group B(medial patellar taping) considered extremely significant with $p$-value $<0.0001$. Comparision between the post test values 
Table 2 : COMPARISON OF PRE AND POST VALUES FOR VAS IN GROUP B

\begin{tabular}{lcccc}
\hline & Mean value & Standard deviation & t-value & p-value \\
\hline PRE & 7.6 & 1.056 & 2.761 & 0.0100 \\
POST & 6.533 & 1.060 & & \\
\hline
\end{tabular}

Table 3 : COMPARISON OF POST VALUES FOR VAS BETWEEN GROUP A AND GROUP B

\begin{tabular}{lcccc}
\hline & Mean value & Standard deviation & t-value & p-value \\
\hline PRE & 3.466 & 1.462 & 6.078 & $<0.0001$ \\
POST & 6.533 & 1.060 & & \\
\hline
\end{tabular}

Table 4: COMPARISON OF POST VALUES FOR KUJALA FUNCTIONAL SCORE IN GROUP A

\begin{tabular}{lcccc}
\hline & Mean value & Standard deviation & t-value & p-value \\
\hline PRE & 46.533 & 8.271 & 13.604 & $<0.0001$ \\
POST & 8.271 & 6.675 & & \\
\hline
\end{tabular}

Table 5 : COMPARISION OF POST VALUES OF KUJALA FUNCTIONALSCORE IN GROUP B

\begin{tabular}{lcccc} 
& Mean value & Standard deviation & t-value & p-value \\
\hline PRE & 47.4 & 8.990 & 3.885 & 0.0006 \\
POST & 60.33 & 9.240 & & \\
\hline
\end{tabular}

Table 6 : COMPARISON OF POST VALUES FOR KUJALA FUNCTIONAL SCORE BETWEEN GROUP A AND GROUP B

\begin{tabular}{lcccc}
\hline & Mean value & Standard deviation & t-value & p-value \\
\hline PRE & 83.866 & 6.675 & 7.551 & $<0.0001$ \\
POST & 61 & 9.644 & & \\
\hline
\end{tabular}

for VAS between Group A and Group B(Table 3) is considered significant with $t$ value 6.078 and post test values for KUJALA FUNCTIONAL SCORE(Table 6) between Group A and Group B is considered extremely significant with t-value 7.551.

\section{DISCUSSION}

Pain and restriction of joint motion is seen in patients with patella femoral pain syndrome.The above results clearly shows that open and closed kinetic chain excercises (Group A) for six weeks significantly reduced pain and improved patellofemoral and knee joint function. These results are in accordance with systematic review done in 2011 stating that the use of quadriceps strengthening excercises are considered to be the gold standard for treatment of patellofemoral pain syndrome ${ }^{7}$. Although reduction in pain and improvement in function occurred in both the Group A and B Group A was signicantly better than group B in reduction of pain and improvement in function. The reason might have been that open and closed kinetic excercises strengthening the Vastus medialis obliqus muscles that improves quadriceps muscle torque and stabilize the patella by preventing abnormal patellar biomechanics which clearly 
indicates that six weeks of combined open and closed kinetic chain exercises were effective in the management of patellofemoral pain syndrome. Motor control is largely managed by retraining of vasti muscles, especially vastus medialis oblique. In this study, therefore combined exercises focused on selective strengthening of vastus medialis oblique, which leads to correction of patella maltracking. By restoration of patella mal alignment decreased pain and improved function are expected, as evidenced by this study. Crossely et, al [2005] also indicated that six weeks of physiotherapy program could increase knee flexion during stair ascent and descent in the patients with patellofemoral pain syndrome ${ }^{5}$. According to crossely et.al improvements in the neuromotor control of the vasti muscles may affect patellar tracking and the process leading to improved function of the subject during gait ${ }^{6 .}$

Open and closed kinetic exercises have been used as treatment protocol in management of patellofemoral pain syndrome. Some studies compared the effect of open and closed kinetic chain exercises in management of this syndrome. HERRINGTON and Al- SHERHI [2007] and WITROUW et.al $[2000,2004]$ concluded that both open and closed kinetic chain exercises jointly useful in treatment of patellofemoral pain ${ }^{14,9}$

It has been fairly well established that taping the patella relieves pain, although the mechanism of the effect is still being debated in the literature

On the other hand,Group B with medial patellar taping reduced pain and improved patellofemoral joint function,the improvement was not significant when compared to Group A. The reduction in pain might have occurred because patellar medial taping effectively prevents abnormal lateral tracking of the patella and aligns the patella increasing the loading response during knee flexion as well as increase in quadriceps muscle torque.Signifgicant improvement did not occur in Group B which is in accordance to a study done by RODRIGUZ-MERCHAN,(2014) showing no significant improvement in pain in taping and non-taping subjects ${ }^{29}$.The reason for lack of significant improvement in Group B may also be due to weakness of the VMO as patellar taping does not strengthen the muscles around the the knee and patellofemoral joint. It has been found that taping the patella of a symptomatic individual, such that the pain is decreased by $50 \%$, results in an earlier activation of the VMO relative to the vastus lateralis (VL) on both step-up and step-down. Stepping down, in particular, caused an $8.3^{\circ}$ differential between the VMO and VL, because not only was the VMO activating earlier than in the pretaped condition but also the VL was significantly delayed in the taped condition. 5 However, in a study done by Cerny et al in which all subjects had a medial tilt and internal rotation of the inferior pole taping, there was no change in activation patterns of the VMO and VL when the subjects were taped ${ }^{30}$.

In this study both GROUPS Group A and Group B reduced pain and improved function of patellofemoral joint. Significant reduction in pain and improved function has been seen in GROUP A in which combined open and closed kinetic exercises were given.

\section{CONCLUSION}

The results of this study have shown significant reduction of pain and improvement in functional ability of patients with Patellofemoral pain syndrome in patients treated with combined open and closed kinetic chain exercises(Group A) when compared to( Group B) that is medial patellar taping. Therefore combined open and closed kinetic chain exercises may be used for better treatment outcome in Patellofemoral Pain Syndrome patients.

\section{REFERENCES}

1. Sanchis-Alfonso, V., 2006. Anterior Knee Pain and Patellar Instability. 1 ed., London: springer.

2. Brechter $\mathrm{JH}$, Powers $\mathrm{CM}$. Patellofemoral joint stress during stair ascent and descent in persons with and without patellofemoral pain. Gait \& Posture. 2002 Oct;16(2):115-23. Available from: http://dx.doi.org/10.1016/s0966-6362(02)00090-5.

3. Green ST. Patellofemoral syndrome. Journal of Bodywork and Movement Therapies. 2005 Jan;9(1):16-26. Available from: http://dx.doi.org/10.1016/j.jbmt.2003.12.001.

4. Thomeé R, Renström P, Karlsson J, Grimby G. Patellofemoral pain syndrome in young women. Scandinavian Journal of Medicine \& Science in Sports. 2007 Jan 30;5(4):245-51. Available from: http://dx.doi.org/10.1111/j.16000838.1995.tb00041.x.

5. Crossley KM, Cowan SM, Bennell KL, McConnell J. Knee flexion during stair ambulation is altered in individuals with patellofemoral pain. J Orthop Res. 2004 Mar;22(2):267-74. Available from: http://dx.doi.org/10.1016/j.orthres.2003.08.014.

6. CROSSLEY KM, COWAN SM, MCCONNELL J, BENNELL KL. Physical Therapy Improves Knee Flexion during 
Stair Ambulation in Patellofemoral Pain. Medicine \& Science in Sports \& Exercise. 2005 Feb;37(2):176-83. Available from: http://dx.doi.org/10.1249/01.mss.0000152676.13197 .49 .

7. Syme G, Rowe P, Martin D, Daly G. Disability in patients with chronic patellofemoral pain syndrome: A randomised controlled trial of VMO selective training versus general quadriceps strengthening. Manual Therapy. 2009 Jun;14(3):252-63. Available from: http://dx.doi.org/10.1016/j.math.2008.02.007.

8. McConnell J. Management of patellofemoral problems. Manual Therapy. 1996 Mar;1(2):60-6. Available from: http://dx.doi.org/10.1054/math.1996.0251.

9. Witvrouw E, Werner S, Mikkelsen C, Van Tiggelen D, Vanden Berghe L, Cerulli G. Clinical classification of patellofemoral pain syndrome: guidelines for nonoperative treatment. Knee Surg Sports Traumatol Arthrosc. 2005 Feb 10;13(2):122-30. Available from: http://dx.doi.org/10.1007/s00167-004-0577-6.

10. Sanchis-Alfonso V, Roselló-Sastre E. Hypothesis: Anterior knee pain in the young patient-what causes the pain?"Neural model."Acta Orthopaedica Scandinavica. 2003 Jan;74(6):697-703. Available from: http://dx.doi.org/10.1080/00016470310018225.

11. Grelsamer, R.P., 2000. Patellar mal-alignment. J Bone Joint Surg. Am., 82-A(11): 1639-50.

12. Cowan SM, Crossley KM. Does gender influence neuromotor control of the knee and hip? Journal of Electromyography and Kinesiology. 2009 Apr;19(2):276-82. Available from: http://dx.doi.org/10.1016/j.jelekin.2007.07.009

13. Kaya, D.C.M., H. Ozkan, F. Ozdag, O.A. Atay,I. Yuksel and M.N. Doral, 2010. The Effect of an Exercise Program in Conjunction With Short-Period Patellar Taping on Pain, Electro myogram Activityand Muscle Strength in Patello femoral Pain Syndrome. Sports Health: A Multi disciplinary Approach, 2: 410-416

14. Herrington L, Pearson S. Does level of load affect relative activation levels of vastus medialis oblique and vastus laterialis? Journal of Electromyography and Kinesiology. 2006 Aug;16(4):379-83. Available from:

http://dx.doi.org/10.1016/j.jelekin.2005.08.003.

16. Crossley, K., K. Bennell, S. Green and J. McConnell,2001. A systematic review of physical interventions.

17. Fagan V, Delahunt E. Patellofemoral pain syndrome: a review on the associated neuromuscular deficits and current treatment options. British Journal of Sports
Medicine. 2008 Oct 1;42(10):489-95. Available from: http://dx.doi.org/10.1136/bjsm.2008.046623.

18. Fredericson M, Powers CM. Practical Management of Patellofemoral Pain. Clinical Journal of Sport Medicine. 2002 Jan;12(1):36-8. Available from: http://dx.doi.org/10.1097/00042752-20020100000010.

19. NATRI A, KANNUS $P$, J??RVINEN $M$. Which factors predict the long-term outcome in chronic patellofemoral pain syndrome? A 7-yr prospective follow-up study. Medicine \& Science in Sports \& Exercise. 1998 Nov;30(11):1572-7. Available from: http://dx.doi.org/10.1097/00005768-19981100000003.

20. Barton CJ, Webster KE, Menz HB. Evaluation of the Scope and Quality of Systematic Reviews on Nonpharmacological Conservative Treatment for Patellofemoral Pain Syndrome. Journal of Orthopaedic \& Sports Physical Therapy. 2008 Sep;38(9):529-41. Available from: http://dx.doi.org/10.2519/jospt.2008.2861.

21. Kramer PG. Patella Malalignment Syndrome: Rationale to Reduce Excessive Lateral Pressure. Journal of Orthopaedic \& Sports Physical Therapy. 1986 Dec;8(6):301-9. Available from: http://dx.doi.org/10.2519/jospt.1986.8.6.301.

22. Steinkamp LA, Dillingham MF, Markel MD, Hill JA, Kaufman KR. Biomechanical considerations in patellofemoral joint rehabilitation. The American Journal of Sports Medicine. 1993 Jun 1;21(3):438-44. Available from: http://dx.doi.org/10.1177/036354659302100319.

23. ESCAMILLA RF, FLEISIG GS, ZHENG N, BARRENTINE SW, WILK KE, ANDREWS JR. Biomechanics of the knee during closed kinetic chain and open kinetic chain exercises. Medicine \&amp Science in Sports \&amp Exercise. 1998 Apr;30(4):556-69. Available from: http://dx.doi.org/10.1097/00005768-19980400000014.

24. HUNGERFORD DS, BARRY $M$. Biomechanics of the Patellofemoral Joint. Clinical Orthopaedics and Related Research. 1979 Oct;\&NA;(144):9???15. Available from: http://dx.doi.org/10.1097/00003086197910000-00003.

25. Stiene HA, Brosky T, Reinking MF, Nyland J, Mason MB. A Comparison of Closed Kinetic Chain and Isokinetic Joint Isolation Exercise in Patients With Patellofemoral Dysfunction. Journal of Orthopaedic \& Sports Physical Therapy. 1996 Sep;24(3):136-41. Available from: http://dx.doi.org/10.2519/jospt.1996.24.3.136.

26. Witvrouw, E., R. Lysens, J. Bellemans, K. Peers andG. Vanderstraeten, 2000. Open versus closed kineticchain exercises for patellofemoral pain. 
Aprospective, randomized study. Am. J. Sports Med.,28(5): 687-94.

27. Witvrouw E. Open Versus Closed Kinetic Chain Exercises in Patellofemoral Pain: A 5-Year Prospective Randomized Study. American Journal of Sports Medicine. 2004 May 18;32(5):1122-30. Available from: http://dx.doi.org/10.1177/0363546503262187.

28. Bakhtiary $\mathrm{AH}$, Fatemi E. Open versus closed kinetic chain exercises for patellar chondromalacia. British Journal of Sports Medicine. 2007 Jun 4;42(2):99-102.
Available

http://dx.doi.org/10.1136/bjsm.2007.038109.

29) E.Carlps Rodriguez-Merchan,MD,2014.Evidence Based Conservative Management of Patello-femoral Syndrome.Arch Bone Jt Surg.,Mar;2(1):4-6.

30) Kay Cerny (August 1995). Vastus Medialis Oblique/Vastus Lateralis Muscle Activity Ratios for Selected Excercises in Persons With and Without Patelloifemoral Pain Syndrome. 